\title{
Desain Interaksi Game Edukasi Rantai Makanan Menggunakan Teknologi Mobile Augmented Reality
}

\author{
REZKI YUNIARTI, AGUS KOMARUDIN \\ Fakultas Sains dan Informatika, Jurusan Informatika \\ Universitas Jenderal Achmad Yani \\ rezkiy@gmail.com
}

\begin{abstract}
ABSTRAK
Tinjauan studi $A R$ secara empiris dalam pendidikan yang telah dipublikasikan jurnal SSCI terindeks SSCI dari 2011 hingga 2016, ditemukan bahwa sejumlah studi AR di bidang pendidikan telah meningkat secara signifikan sejak 2013. Temuan dalam penelitian tersebut dapat mengungkapkan pentingnya penerapan $A R$ yang efektif dalam pendidikan, dan memberikan arah yang potensial untuk penelitian di masa depan. Desain interaksi yang baik menghasilkan interaksi antara pengguna dengan perangkat lunak, dibutuhkan supaya pengguna dapat menerima materi pembelajaran yang diberikan oleh edugame. Bentuk interaksi serta gameplay yang dibuat akan mempengaruhi seberapa tertariknya pengguna terhadap topik pembelajaran yang disajikan. Akan dibuat sebuah desain interaksi serta implementasi edugame bertema rantai makanan menggunakan teknologi Mobile Augmented Reality. Dalam menghasilkan desain interaksi menggunakan pendekatan komponen: learning objectives, dan framework MDA. Hasil luaran penelitian adalah berupa desain edugame mobile AR. Sebanyak 36\% pengguna setuju menggunakan pembelajaran berbasis multimedia, dan setelah penggunaan aplikasi, $72 \%$ setuju pengguna lebih memahami materi jika disampaikan menggunakan multimedia/aplikasi tersebut. Hasil dari evaluasi prototype adalah sebanyak $63,6 \%$ pengguna dapat mengingat materi yang disajikan.
\end{abstract}

Kata kunci : desain interaksi, mobile augmented reality, platform MDA

\begin{abstract}
An empirical review of AR studies in SSCI-indexed journals from 2011 to 2016 found that a number of AR studies in education have improved significantly since 2013. The findings in this study may reveal the importance of effective AR application in education, and provide potential direction for future research. Good interaction design results in interaction between the user and the software, required for the user to receive the learning materials provided by edugame. The form of interaction and the gameplay that is created will affect how interested the user to the learning topic presented. There will be an interaction design and implementation of food chain themed edugame using Mobile Augmented Reality technology. In producing interaction design using component approach: learning
\end{abstract}


objectives, and MDA framework. The output of the research is in the form of edugame mobile AR design. As many as $36 \%$ of users agree to use multimediabased learning, and after application usage, 72\% agree users better understand the material when delivered using the multimedia / app. The result of the prototype evaluation is $63.6 \%$ of users can remember the material presented..

Keywords : Interaction design, mobile augmented reality, MDA Platform

\section{PENDAHULUAN}

Pembelajaran menggunakan teknologi Augmented reality (selanjutnya disebut AR), telah digunakan di berbagai macam Permainan pada smartphone. Pada tahun 2016, inovasi teknologi pembelajaran sangat terkonsentrasi di empat jenis produk pembelajaran, yaitu: Pembelajaran berbasis simulasi, berbasis permainan, Pembelajaran Kognitif, dan Mobile Learning (Adkins, 2017). Diasumsikan bahwa edugame mempengaruhi pembelajaran dalam dua cara, dengan mengubah proses kognitif dan dengan mempengaruhi motivasi. Namun, hingga kini penelitian telah menunjukkan sedikit bukti untuk asumsi ini. Dengan menggunakan teknik meta-analisis, menghasilkan bahwa edugame lebih efektif dalam pembelajaran dan lebih memotivasi daripada metode pengajaran konvensional (Wouters et al, 2013). Telah banyak penelitian yang menghasilkan kesimpulan bahwa Edugame dirasa efektif untuk menyampaikan suatu materi atau bahan ajar (Yuniarti and Komarudin, 2013)(Haswan and Al-Hafiz, 2016). Temuan dalam penelitian tersebut dapat mengungkapkan pentingnya penerapan AR yang efektif dalam pendidikan, dan memberikan arah yang potensial untuk penelitian di masa depan (Chen et al, 2016).

Penelitian ini bertujuan membuat sebuah desain interaksi serta implementasi edugame bertema rantai makanan menggunakan teknologi Mobile Augmented reality. Dalam menghasilkan desain interaksi yang cukup layak membutuhkan desain edugame dengan menggunakan pendekatan komponen: learning objectives, dan framework MDA.

\section{KAJIAN LITERATUR}

Objek fisik mampu memberikan interaksi yang lebih natural daripada alat masukan komputer seperti mouse dan keyboard, serta berpotensi membuat pengguna lebih mengingat materi karena tindakan motorik yang ia lakukan (Bujak et al, 2013). Ketika objek 3D divisualisasikan dengan menggunakan marker berupa flashcard juga akan memberikan user experience (selanjutnya disebut UX) yang menyenangkan, dimana pengguna akan lebih memahami topik yang diajarkan oleh pendidik, namun akan lebih baik jika kemudian objek tersebut memiliki kecerdasan buatan (Mahale and Yeddu, 2016). Kecerdasan buatan seringkali digunakan untuk pembuatan karakter, agar memiliki prilaku yang setidaknya lebih otomatis. Keberadaan NPC yang dapat bertingkah karena pengaruh lingkungannya pada suatu permainan komputer sangatlah penting agar terdapat kesan nyata. Namun pada beberapa permainan komputer, tokoh yang sangat pintar justru dihindari agar tidak memberikan tantangan yang tidak dapat diselesaikan oleh pemain. Penentuan sifat karakter sangat dipengaruhi oleh genre permainan (Glasser and Soh, 2004). Edugame rantai makanan pernah dikerjakan dengan menghasilkan dua buah karakter yang memiliki pergerakan otomatis (Komarudin and Yuniarti, 2016)(D. Worlds, 2017). Namun belum berfokus kepada desain interaksi. Karakter 3D yang divisualisasi akan memiliki prilaku serta terintegrasi sehingga memberikan UX yang lebih menarik dibandingkan penelitian sebelumnya (Octagon Studio, 2016)(Bujak et al, 2013)(Mahale and Yeddu, 2016). Pembuatan desain edugame pada penelitian terdahulu menggunakan pendekatan MDA (Mechanics, Dynamics, and Aesthetics) (Hunicke et al, 2004). 
MDA menjawab sebuah cara untuk mencoba menjembatani kesenjangan antara desain game dan pengembangan, kritik pada game, dan penelitian pada teknis game. MDA juga digunakan pada penelitian sebelumnya, dimana membahas satu kesatuan framework yang terdiri dari 3 komponen, yaitu: learning objectives, MDA, dan Instructional Design Principles, strategi untuk menggabungkan ketiganya membantu desainer untuk mengidentifikasi dan menganalisis pilihan desain penting yang perlu dibuat saat membuat game edukasi (Aleven et al, 2010).

Framework MDA (Mechanics, Dynamics, and Aesthetics), dikembangkan sebagai bagian dari desain game. MDA adalah pendekatan formal untuk memahami game, salah satunya mencoba untuk menjembatani antara desain game, pengembangan, kritik/tanggapan tentang game, penelitian teknologi game. MDA akan memperjelas dan memperkuat proses yang terjadi diantara pengembang, penguji/pemain, peneliti (Hunicke et al, 2004). Konsumsi produk hiburan seperti game tidak dapat ditebak apakah akan bertahan lama ataupun mudah dilupakan. MDA memformalkan proses konsumsi game dengan memecahnya menjadi beberapa komponen seperti pada Gambar 1.

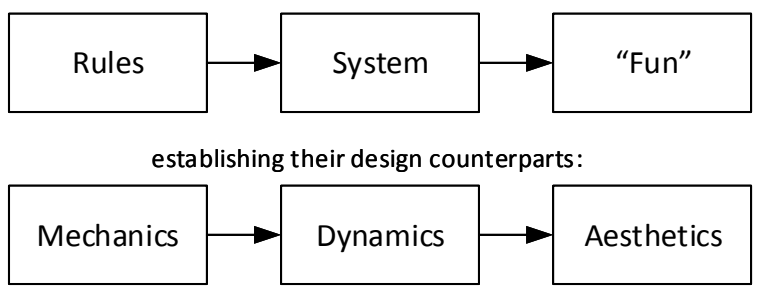

Gambar 1. Komponen hasil "breaking" proses konsumsi game, menjadi MDA

Berdasarkan Framework tersebut, terdapat tiga proses dalam merancang game, yaitu:

Mekanik (M) : menggambarkan komponen tertentu dari permainan, di tingkat representasi data dan algoritma.

- Dinamika (D) : menggambarkan perilaku run-time dari mekanik yang bekerja pada input pemain dan saat bersamaan - output dari waktu ke waktu.

- Estetika (A) : menjelaskan respon emosional yang diinginkan terbangkitkan saat pemain berinteraksi dengan sistem permainan.

Dalam hal mendesain game, dapat menggunakan framework MDA (Hunicke et al, 2004) (Marklund, 2013). Namun edugame berbeda, di dalam framework mendesain edugame memiliki komponen learning objectives (Aleven et al, 2010). Sehingga tidak MDA saja, komponen yang telah dikemukakan pada penelitian sebelumnya yang membahas mengenai framework untuk mendesain edugame, terdiri dari 3 komponen yaitu: learning objectives, MDA, dan Instructional Design Principles juga dapat dilakukan (Aleven et al, 2010). MDA sendiri adalah framework untuk mendesain game.

Desain interaksi adalah sebuah proses yang terdiri dari: aktivitas pemecahan masalah terarah pada tujuan penggunaan yang dimaksudkan, target domain, bahan, biaya, dan kelayakan; aktivitas kreatif; kegiatan pengambilan keputusan sebagai penyeimbang. Terdapat 4 kegiatan utama pada Desain Interaksi (Preece et al, 2015), yaitu:

1. Mengidentifikasi kebutuhan dan menentukan persyaratan/requirements

2. Mengembangkan desain alternatif 
3. Membangun versi interaktif dari desain

4. Mengevaluasi desain

Kegiatan tersebut terlihat pada Gambar 2 yang selanjutnya disebut sebagai pendekatan terpusat kepada user.

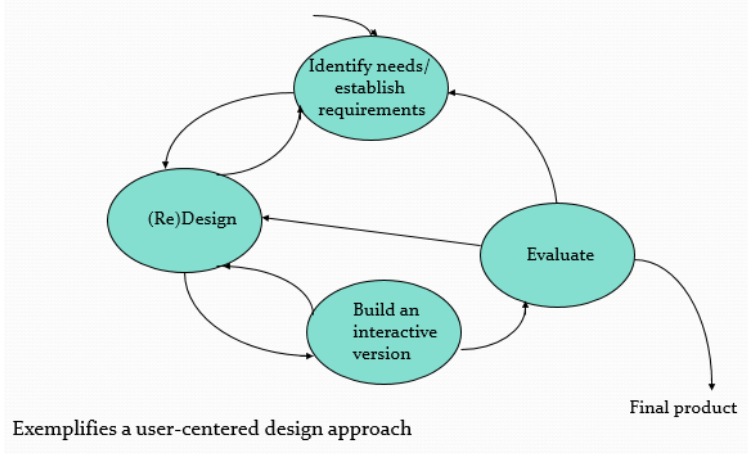

\section{Gambar 2. Pendekatan desain interaksi menggunakan User-Centered Design}

(Preece et al, 2015)

Pada penelitian sebelumnya teknologi AR digunakan pada pembelajaran matematika, serta mendiskusikan bagaimana physical affordance pada AR memberikan pengalaman yang menguntungkan bagi siswa untuk pembelajaran (Bujak et al, 2013). Sementara pada penelitian lain menyampaikan bahwa mobile AR dapat digunakan untuk meningkatkan literasi di usia dini, dengan cara memanfaatkan kekuatan motivasi untuk meningkatkan minat dan kemampuan AR untuk melibatkan anak dalam berlatih menggunakan aksara berbasis cetak. Anak dapat menggambarkan huruf dan melihatnya dalam bentuk 3D (Bhadra et al, 2016).

Penggunaan teknologi AR disarankan, hal ini dibuktikan bahwa pada penelitan sebelumnya membahas mengenai penggunaan teknologi AR dalam Pendidikan formal dan terjadi peningkatan pembelajaran dan pemahaman setelah menggunakan teknologi AR. Terjadi peningkatan pada perhatian, keterlibatan siswa pada pembelajaran, siswa memiliki rasa ketertarikan dan motivasi (Saltan and Arslan, 2016).

Bahan pembelajaran bertema kesehatan gigi dengan teknologi mobile AR juga pernah dibuat dan hasil dari pengujian kepada 50 responden, $42 \%$ menyatakan sangat informatif, dan $54 \%$ menyatakan informatif. Kemudian $44 \%$ setuju bahwa aplikasi sangat membantu memahami tentang gigi berlubang, $50 \%$ menyatakan aplikasi membantu memahami gigi berlubang (Budiman, 2017).

Desain karakter dan pemodelan prilakunya menggunakan FSM dan Fuzzy Tsukamoto pada edugame rantai makanan menggunakan teknologi mobile AR juga telah dilakukan, yaitu untuk karakter ular (Komarudin and Yuniarti, 2016), sehingga karakter ini akan digunakan dan diintegrasi dengan karakter lainnya.

Tema yang akan dibahas pada edugame adalah tema Rantai makanan pada lingkungan sawah. 


\section{ANALISIS DAN PERANCANGAN}

Proses desain game yang akan dibuat, menggunakan framework MDA. Pada framework MDA sendiri telah menghasilkan user experience. Untuk mencapai pemahaman yang baik terhadap permasalahan yang ada, dilakukan dengan melibatkan pengguna saat proses desain sejak dini. Sehingga dengan pendekatan UCD, akan dilakukan seperti pada Gambar 2.

Metode pembuatan desain interaksi salah satunya adalah menggunakan pendekatan User Centered Design (UCD) dapat dilihat seperti pada Gambar 1, secara detail metode yang akan dilakukan pada penelitian dapat dilihat seperti pada Gambar 3.

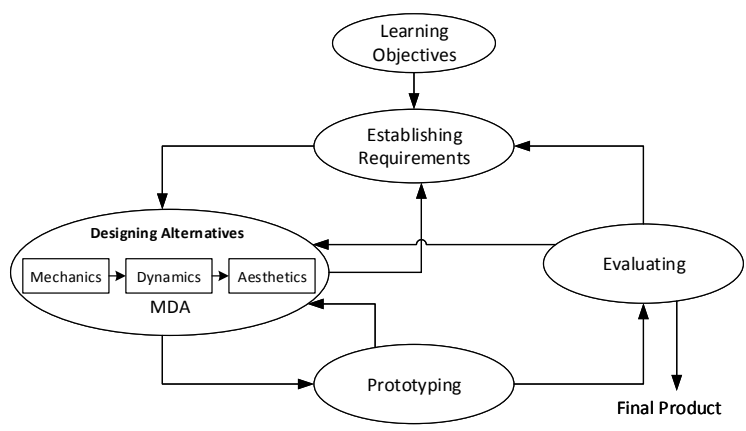

Gambar 3. Proses desain interaksi edugame rantai makanan menggunakan UCD (framework learning objectives dan MDA di dalam UCD)

\subsection{Learning Objectives}

Menentukan learning objectives membutuhkan menjawab tiga pertanyaan berikut ini (Aleven et al, 2010):

a) Prior Knowledge. Pengetahuan atau keterampilan apa saja yang harus dimiliki oleh siswa/pengguna sebelum memulai permainan?

Siswa pernah mempelajari macam-macam hewan, jenis hewan dan makanannya. Siswa mengetahui hewan herbivora, karnivora dan omnivora.

b) Learning dan retention. Pengetahuan atau keterampilan apa saja yang diharapkan didapat/dipelajari dari permainan?

Sesuai dengan KTSP, kompetensi dasar adalah siswa memahami hubungan antara makan dan dimakan. Dalam rantai makanan, dapat membedakan mahluk hidup berdasarkan jenis makanannya yaitu mahluk hidup sebagai produsen dan konsumen

c) Potential transfer. Pengetahuan dan keterampilan apa saja yang mungkin dipelajari melampaui apa yang sebenarnya mereka temui dalam permainan?

Mengetahui jenis hewan berdasarkan makanannya (herbivora, karnivora atau omnivore) serta membedakan berdasarkan atas hewan sebagai produsen atau konsumen tingkat 1 , konsumen tingkat 2. Mengetahui rantai makanan pada lingkungan sawah. Mengetahui rantai makanan adalah bentuk hubungan antara mahluk hidup. Jika menggabungkan hewan dalam satu lingkungan akan terbentuk rantai makanan. 
Aleven berpendapat (Aleven et al, 2010), bahwa menjawab pertanyaan-pertanyaan ini memerlukan: (a) menyediakan spesifikasi tertulis dari pengetahuan dan keterampilan, (b) memberikan contoh tugas-tugas (tasks) dimana pengguna akan meningkatkan pengetahuan dan keterampilan yang diberikan, (c) mengkategorikan pengetahuan, keterampilan dan tugas-tugas (tasks) menggunakan Taxonomi Bloom.

Tabel 1. Penentuan Learning Objectives

\begin{tabular}{|l|l|}
\hline \multicolumn{1}{|c|}{ Prior Knowledge } & \multicolumn{1}{|c|}{ Mengetahui hewan } \\
\hline Learning dan retention & $\begin{array}{l}\text { Menggolongkan hewan berdasarkan jenis makanannya } \\
\text { (lihat Gambar 2.5). }\end{array}$ \\
\hline Potential transfer & $\begin{array}{l}\text { Proses memakan dan dimakan, membentuk rantai } \\
\text { makanan }\end{array}$ \\
\hline
\end{tabular}

Dalam rangka menetapkan requirements, harus dilakukan penelitian terlebih dahulu. Dilakukan survey untuk pre-desain. Dipilih pengguna adalah siswa pelajar SD yang mempelajari materi tersebut dengan dilakukan pengisian quisioner. Hasil dari kuisioner cepat (quick and dirty testing) (Marklund, 2013) melibatkan 11 orang pengguna dengan rentang umur siswa 9-11 tahun yang telah dilakukan adalah sebagai berikut ini:

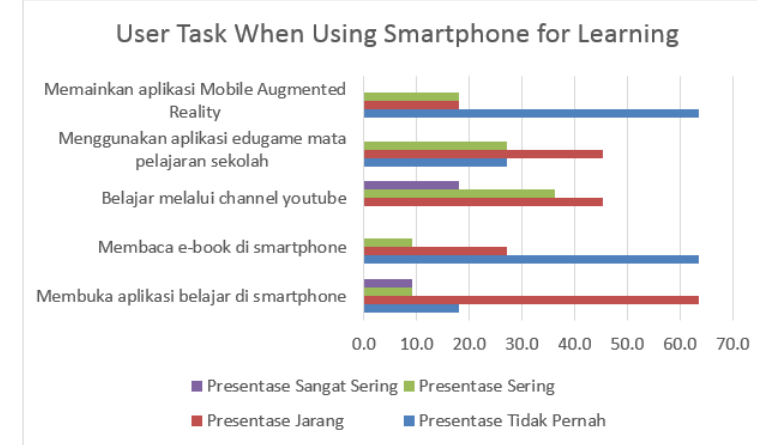

Gambar 4. User's task saat menggunakan aplikasi pembelajaran di smartphone

\subsection{Mengembangkan Desain Alternatif}

Mengembangkan desain game akan menggunakan framework MDA.

\subsubsection{Mechanics}

Tahap mechanics, menggambarkan komponen, data dan algoritma. Juga menggambarkan apa yang dilakukan oleh pemain, interaksi inti yang terjadi di dalam game, aturan dari game. Sehingga semuanya akan mengakibatkan pada pemrograman. Komponen yang terdapat pada game diperkirakan akan terdiri dari:

a) Interaksi pemain terhadap aplikasi

Pemain dapat berinteraksi dengan aplikasi melalui beberapa mode. Interaksi terdiri dari:

i) Pemain dapat mempelajari mengenai karakter hewan (jenis makanan dan merupakan konsumen tingkat berapa)

ii) Pemain dapat mengamati hubungan rantai makanan antar hewan pada lingkungan sawah dengan memilih virtual button MAR. 
iii) Pemain berinteraksi dengan menggunakan virtual button. Dapat menggunakan virtual button mobile augmented reality, dan stick ice cream sebagai pemilih virtual button

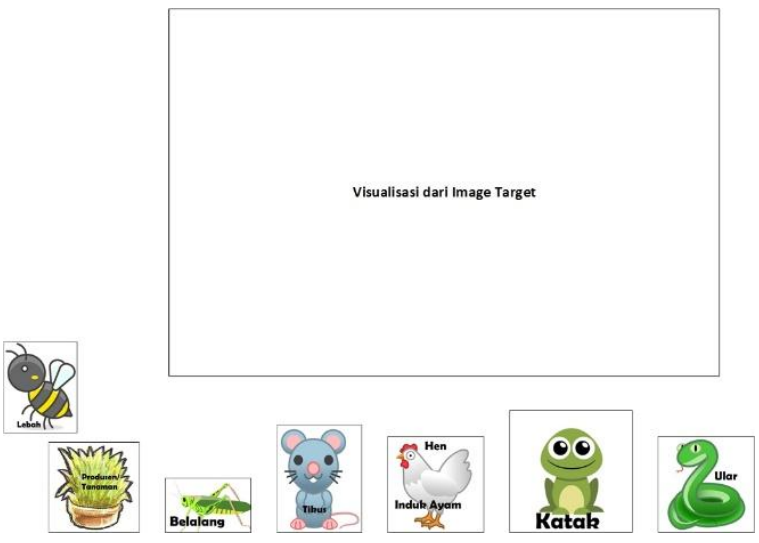

\section{Gambar 5. Halaman/marker untuk melakukan interaksi terhadap MAR Rantai Makanan}

b) Karakter Game

Di dalam game terdapat beberapa non playable character(NPC). Seluruh karakter dalam edugame rantai makanan adalah NPC, namun trigger pergerakannya dimulai dari pengguna.

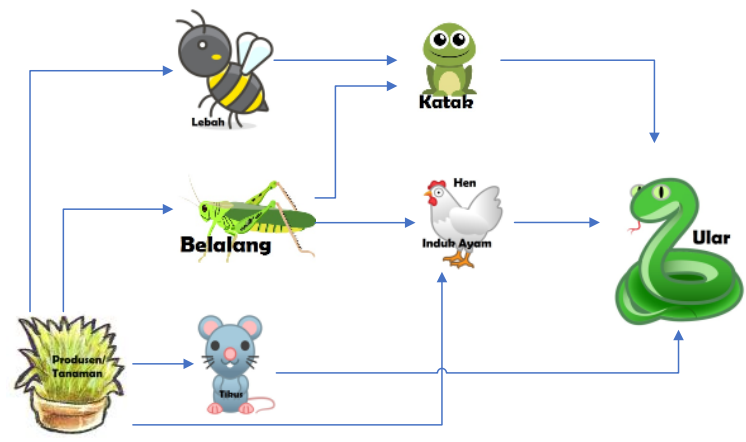

\section{Gambar 6. Rantai makanan yang terjadi serta karakternya}

c) Pemodelan karakter hewan. Secara umum memiliki dua tahapan :

i) Visualisasi karakter (jenis makanan dan jenis golongan produsen/konsumen), divisualisasikan menggunakan teknologi mobile augmented reality

ii) Karakter dapat memakan dan dimakan, divisualisasi dalam dunia AR Virtual Button

iii) Visualisasi karakter akan mempengaruhi karakter lain yang memiliki hubungan pada rantai makanan

iv) Karakter memiliki state animasi yang dimodelkan pada class Animator.

v) Karakter menghitung jalur yang dilalui tanpa hambatan dan berpindah menuju makanan, jika pemain memberi trigger makan.

Karakter yang akan muncul harus mewakili jenis hewan dari masing-masing sifatnya berdasarkan jenis makanan, yaitu karnivora, herbivora, omnivore dan insectivore, mengingat lingkungan adalah daerah sawah, tidak akan melibatkan karnivora seperti predator pada lingkungan savana. Adapun karakter yang direncanakan disini adalah :

a) Herbivora : Lebah, belalang, ayam

b) Karnivora : Ular 
c) Omnivora : Tikus

d) Insektifora : Kodok/katak

e) Rerumputan atau pohon sebagai produsen

\subsubsection{Dynamics}

Dynamic merupakan perancangan apa yang akan terjadi di dalam game. Terdapat rule dan bagaimana mechanics berinteraksi terhadap assets. Apa yang terjadi di dalam dynamics akan mempengaruhi aesthetics yang diterima oleh pemain. Di dalam dynamic akan muncul assets yang diperlukan. Akan diperlukan model objek 3D sesuai dengan karakter yang terdapat di rantai makanan seperti pada Gambar 6 maka character serta rancangan Kelas Animator nya adalah NPC Lebah, NPC NPC Belalang, NPC Tikus, NPC Ular, NPC Ayam, NPC Katak serta model 3D untuk produsen. Salah satu contoh asset NPC Lebah seperti pada Gambar 7.

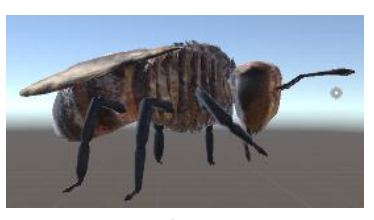

Tampak samping

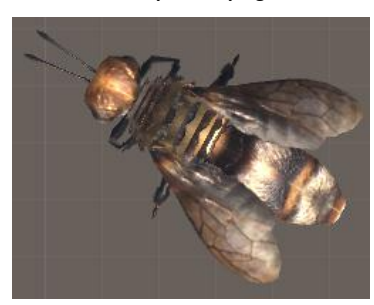

Tampak atas

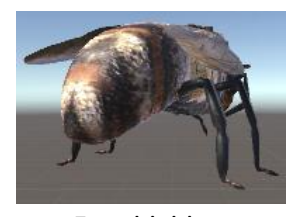

Tampak belakang

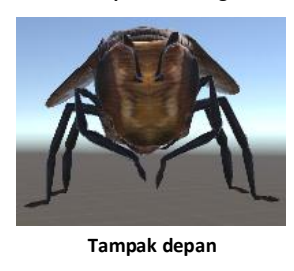

Tampak depan

Gambar 7. Model 3D NPC lebah

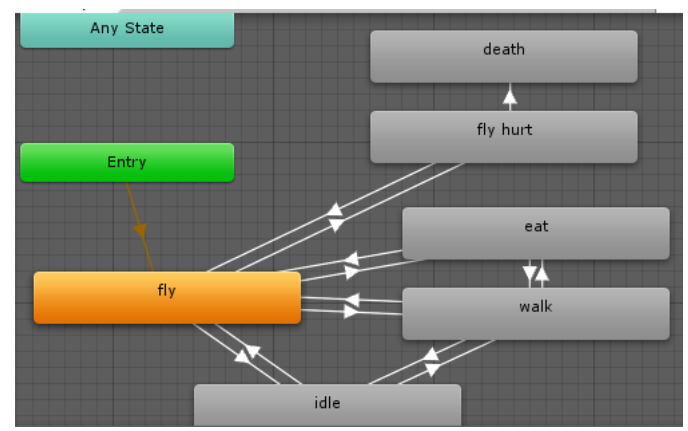

Gambar 8. Base layer Animator pada lebah

Dan seterusnya untuk NCP lainnya.

\subsubsection{Aesthetics}

Pada proses ini mendapatkan respon emosional yang diinginkan pada saat pengguna bermain game. Asthetics tidak hanya membiarakan graphics, namun akan menghasilkan efek/akibat dari dynamic pada pemain. Berdasarkan taxonomi dari aesthetics, taxonomi aesthetics yang paling sesuai untuk edugames adalah Discovery. Untuk mencapai hal tersebut, pengguna dapat menciptakan sendiri rantai makanannya dengan cara memvisualisasikan flash card yang disediakan. Dan juga memilih objek untuk divisualisasikan pada rantai makanan. Objek hewan yang telah memiliki prilaku akan bertindak secara otomatis sesuai yang telah dirancang dalam Gambar 5. 


\subsection{Keluaran, Prototype, Desain, dan Aplikasi}

Berdasarkan perancangan pada framework MDA, aplikasi yang dihasilkan mampu berjalan di atas smartphone dan mempergunakan camera smartphone untuk membaca image target. Terdapat dua bagian pembelajaran. Pertama Adalah pemain dapat melihat informasi status dari karakter yang mana akan terdapat visualisasi objek hewan dan keterangan jenis makanan yang dimakan. Sementara untuk scene lainnya, pemain dapat melihat visualisasi rantai makanannya sesuai dengan pemilihan virtual button pada halaman berbeda. Maka didapatkan hasil seperti berikut ini, dimana terdapat dua scene pada aplikasi.

1. Scene Hewan pada rantai makanan

Scene ini berisi aplikasi MAR untuk memvisualisasikan jenis hewan dan golongan makanannya berdasarkan jenis makanannya yaitu, herbivora, omnivore, insectivore. Serta keterangan termasuk produsen atau konsumen tingkat 1 dan 2.

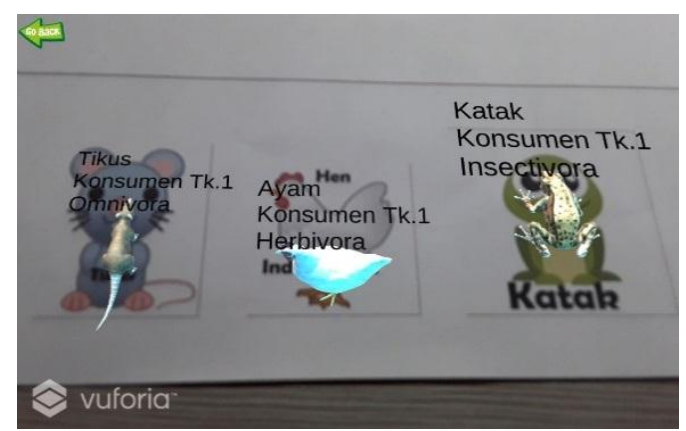

Gambar 9. Pengenalan multiple image target menggunakan marker pada scene 2

2. Rantai Makanan AR

Scene ini berisi aplikasi MAR untuk memvisualisasikan jenis hewan dan golongan makanannya berdasarkan masukkan yang diterima melalui virtual button dari pemain. Dibuat sebuah image target seperti pada Gambar 5.

Pada scene ini pemain memilih hewan yang ingin divisualisasikan rantai makanannya, serta dapat menekan button "makan". Untuk setiap hewan terpilih, akan tampil rantai makanannya. Namun untuk produsen akan selalu tampil.

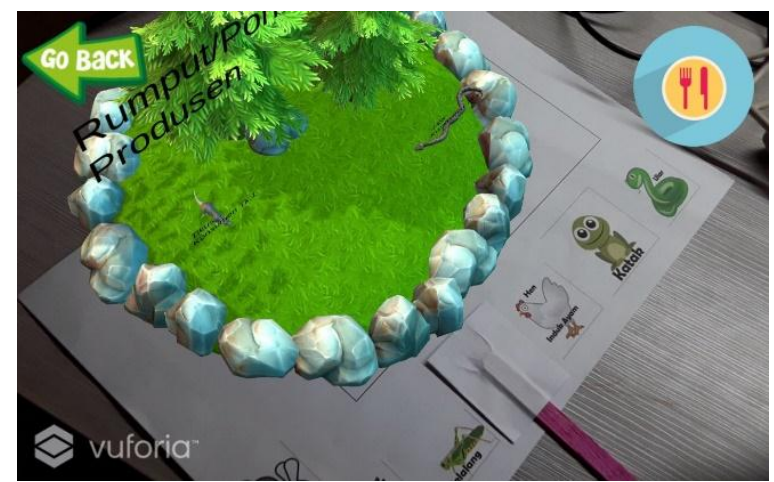

Gambar 10. Pemilihan virtual button tikus akan menyebabkan hanya hewan pada rantai makanan tikus saja yang aktif. 


\section{EVALUASI}

Evaluasi adalah proses penentuan pengukuran dari kegunaan dari suatu produk atau desain yang diukur, membutuhkan keterlibatan pengguna di seluruh pembangunan, dan ini meningkatkan kemungkinan produk dapat diterima oleh pengguna. Dilakukan evaluasi secara langsung di sekolah dasar kepada beberapa siswa kelas 4 dan 5 . Metode evaluasi akan menggunakan quick and dirty testing (Preece et al, 2015), dihasilkan seperti pada Gambar 11.

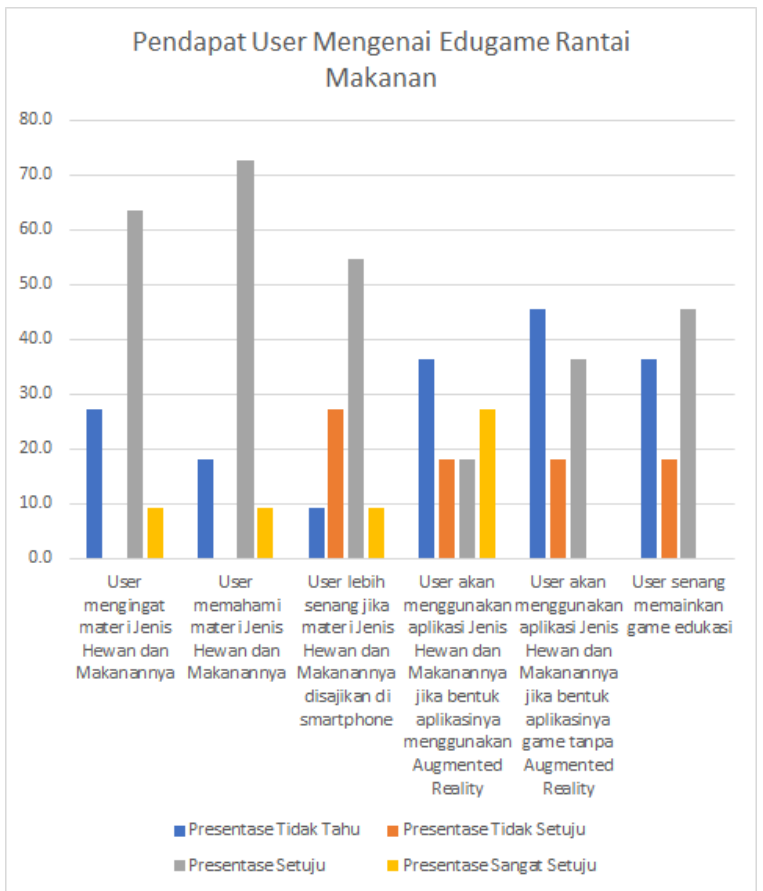

Gambar 11. Evaluasi mengenai edugame Rantai Makanan

\section{KESIMPULAN DAN SARAN}

Desain edugame telah dilakukan dengan menggunakan pendekatan komponen: learning objectives, dan framework MDA. Sebanyak 36\% pengguna setuju menggunakan pembelajaran berbasis multimedia, dan setelah penggunaan aplikasi, $72 \%$ setuju pengguna lebih memahami materi jika disampaikan menggunakan multimedia/aplikasi tersebut. Hasil dari evaluasi prototype versi pertama adalah sebanyak $63,6 \%$ pengguna dapat mengingat materi yang disajikan. Pengguna yang diuji berpendapat $18,2 \%$ setuju dan $27,3 \%$ sangat setuju akan menggunakan aplikasi Jenis Hewan dan Makanannya yang menggunakan Augmented reality. Artinya kurang dari setengahnya menyetujui hal ini. Dikarenakan pengguna masih kesulitan memegang perangkat keras sekaligus melakukan control terhadap stick pemilih virtual button. Saat pengujian digunakan perangkat berukuran 10", yang mana kurang sesuai dengan kondisi pengguna. Kondisi perangkat keras dan pengguna harus disesuaikan dan harus ergonomis. Tangan anak kecil kurang bisa mengendalikan dua perangkat sekaligus jika salah satunya adalah perangkat berukuran besar. Kondisi sebagian pengguna, telah mengetahui gameplay pada game Mobile Legend. Hal ini diketahui melalui survey pendapat pada pengguna mengenai saran aplikasi edugame berikutnya. 


\section{DAFTAR PUSTAKA}

\section{Rujukan Buku:}

J. A. Glasser and L.-K. Soh, "AI in Computer Games: From the Player's Goal to AI's Role," University of Nebraska-Lincoln, Lincoln, 2004.

J. Preece, H. Sharp and Y. Rogers, Interaction Design: Beyond Human-Computer Interaction [4 ed.], New York: Wiley, 2015.

B. B. Marklund, "Games in Formal Educational Settings, Obstacles for the development and use of learning games," University of Skövde, Sweden, 2013.

\section{Rujukan Jurnal:}

P. Wouters, C. Van Nimwegen, H. van Oostendorp and E. D. van der Spek, "A Meta-Analysis of the Cognitive and Motivational Effects of Serious Games," Journal of Educational Psychology, vol. 105(2), pp. 249-265, 2013.

F. Haswan and N. W. Al-Hafiz, "Aplikasi Game Edukasi Ilmu Pengetahuan Alam," Riau Journal Of Computer Science, vol. 3, no. 1, pp. 31- 40, 2016.

P. Chen, X. Liu, W. Cheng and R. Huang, "A review of using Augmented Reality in Education from 2011 to 2016," in Innovations in Smart Learning, Singapore, Springer Science Business Media , 2016, pp. 13-18.

K. R. Bujak, I. Radu, R. Catrambone, B. Macintyre, R. Zheng and G. Golubski, "A Psychological Perspective on Augmented Reality in The Mathematics Classroom," Journal Computers \& Education, vol. 68, pp. 536-544, 2013.

P. Mahale and S. Yeddu, "Android-based Augmented Reality to Enhance Education System," International Journal of Computer Applications, vol. 146, no. 6, pp. 18-21, 2016.

F. Saltan and O. Arslan, "The Use of Augmented Reality in Formal Education: A Scoping Review," EURASIA Journal of Mathematics Science and Technology Education, vol. 13, no. 2, pp. 503-520, 2016.

A. A. Budiman, "Aplikasi Mobile Augmented Reality Berbasis Android Sebagai Media Pembelajaran Gigi Berlubang," Jurnal Teknik dan Ilmu Komputer, vol. 21, no. 06, pp. 63-70, 2017.

\section{Rujukan Prosiding:}

S. S. Adkins, "The 2016-2021 Worldwide Game-based Learning Market," in Serious Play Conference, North Carolina, 2016.

R. Yuniarti and A. Komarudin, "Rancang Bangun Interaksi Pembelajaran Drill Menggunakan Pendekatan User Centerd Design (UCD) Untuk Game Pengingat Resep Masakan," in Seminar Nasional Informatika dan Aplikasinya, Cimahi, 2013.

A. Komarudin and R. Yuniarti, "Desain Dan Implementasi Non Playable Character Pada Permainan Edukasi Rantai Makanan Untuk Konsumen Tingkat 3 (Ular) Berteknologi Mobile Augmented Reality," in Seminar Nasional Aptikom, Mataram, 2016.

R. Hunicke, M. LeBlanc and R. Zubek, "MDA: A Formal Approach to Game Design and Game Research," in Challenges in game artificial intelligence, AAAI workshop, Menlo Park, 2004.

V. Aleven, E. Myers, M. Easterday and A. Ogan, "Toward a framework for the analysis and design of educational games," in 3rd IEEE Conference on Digital Game and Intelligent Toy Enhanced Learning (DIGITEL), Taiwan, 2010.

B. Sawyer and P. Smith, "Serious games taxonomy," in Game Developers Conference, 2008.

A. Bhadra, J. Brown, H. Ke, C. Liu, E.-J. Shin, X. Wang and A. Kob, "ABC3D - Using An Augmented Reality Mobile Game to Enhance Literacy in Early Childhood," in IEEE 
International Conference on Pervasive Computing and Communications Work in Progress, Sydney, 2016.

\section{Rujukan Sumber Online:}

O. Studio, "Octagon Studio 4D+," Octagon Studio, 2016. [Online]. Available: https://www.octagonstudio.com/4d/id. [Accessed 10 Maret 2017].

D. Worlds, "Dino on My Desk," Deepblue Worlds Inc., 26 Februari 2017. [Online]. Available: http://www.dinoonmydesk.com/. [Accessed 10 Maret 2017]. 